\title{
Neutrophil Proteinases in Hydrochloric Acid- and Endotoxin-Induced Acute Lung Injury: Evaluation of Interstitial Protease Activity by In Situ Zymography
}

\author{
Andry Van de Louw, Daniel Jean, Eric Frisdal, Charles Cerf, Marie-Pia d'Ortho, \\ Andrew H. Baker, Chantal Lafuma, Philippe Duvaldestin, Alain Harf, and \\ Christophe Delclaux
}

\begin{abstract}
INSERM U 492 (AVdL, DJ, EF, CC, M-PdO, CL, AH, CD), Université Paris XII, Département d'AnesthésieRéanimation (A Van de L, CC, PD) and Service de Physiologie (M-PdO, $A H, C D$ ), Explorations Fonctionnelles (Assistance Publique-Hôpitaux de Paris), Hôpital Henri Mondor, 94010 Créteil, France; and Department of Medicine and Therapeutics (AHB), University of Glasgow, United Kingdom
\end{abstract}

\begin{abstract}
SUMMARY: We investigated the role of polymorphonuclear neutrophil (PMN) proteinases, elastase, and gelatinase B in rat models of acute lung injury. Three groups of rats were studied 6 hours after unilateral instillation of hydrochloric acid $(\mathrm{HCl} ; 0.1$ $\mathrm{N}$ ), lipopolysaccharide (LPS) $(4 \mu \mathrm{g})$, or saline. The results demonstrated that $\mathrm{HCl}$-induced lung injury, as compared with LPS-induced lung injury, was associated with an increase in permeability (wet/dry weight ratio and proteins in bronchoalveolar lavage fluid). In contrast, there was similar PMN recruitment (in bronchoalveolar lavage fluid and myeloperoxidase activity in lung homogenates) and similar proteinase exocytosis (residual alveolar PMN content of elastase and gelatinase B) in both types of lung injury. In situ zymography, evaluating interstitial protease/inhibitor balance, demonstrated a decrease in gelatinolytic activity in both $\mathrm{HCl}$ - and LPS-injured lungs compared with normal lung. The increase in interleukin 6 concentration in lung homogenates, which is observed after both injuries compared with saline-instilled animals, could be involved in up-regulation of tissue inhibitor of matrix metalloproteinase-1, shown by immunocytochemistry to participate in antiproteinase excess. Neither inhibition of alveolar neutrophil influx using a leukocyte elastase inhibitor (EPI-hNE-4) nor inhibition of gelatinase activities by recombinant adenovirus for the human tissue inhibitor of matrix metalloproteinase 1 gene transfer decreased lung edema in $\mathrm{HCl}$-induced injury. These data suggest that PMN proteinases do not contribute to $\mathrm{HCl}$-induced acute lung injury in rats. (Lab Invest 2002 , 82:133-145).
\end{abstract}

$A$ cute respiratory distress syndrome (ARDS) is characterized by a diffuse injury of the alveolar capillary barrier followed by the rapid occurrence of a fibroproliferative process. Polymorphonuclear neutrophil (PMN) proteinases are thought to participate in this injury process; however, several recent studies have demonstrated an excess of antiproteinases rather than an excess of proteinases in bronchoalveolar lavage $(B A L)$ fluid of patients with ARDS (Delclaux et al, 1997a; Sallenave et al, 1999; Weiland et al, 1986; Wewers et al, 1988). This could explain the early accumulation of extracellular matrix evidenced in this syndrome. However, excess antiproteinase activity in the alveoli does not rule out excess proteinase activity in the interstitial space, which may explain the presence of basement membrane degradation products in the airspaces (Kondoh et al, 1992; Torii et al, 1997). This hypothesis remained unresolved mainly because of the difficulty in evaluating proteinase/inhibitor balance in

Received July 26, 2001.

Address reprint requests to: Dr. Christophe Delclaux, Unité INSERM 492, Faculté de Médecine, 8, rue du Général Sarrail, 94010 Créteil, France. E-mail:delclaux@im3.inserm.fr tissues. Fortunately, a recently described assay, namely in situ zymography, allows us to determine this balance in the interstitial compartment (Galis et al, 1994).

Therefore, in the present study, we evaluated the proteinase/antiproteinase balance in both the alveolar and the interstitial compartments, as well as in vivo proteinase exocytosis by neutrophils, at the initial phase of the hydrochloric acid $(\mathrm{HCl})$-induced acute lung injury model in rats.

Our approach was to compare $\mathrm{HCl}$ instillation, which induces PMN recruitment and an increase in alveolarcapillary permeability, with LPS instillation, which is known to induce marked PMN recruitment without severe injury (Delclaux et al, 1997b). We evaluated the two models in terms of proteolytic activities in BAL fluid and in the interstitial compartment to determine whether the higher permeability to protein observed in $\mathrm{HCl}$-induced injury is a result of greater neutrophil degranulation leading to an excess in proteinase activities as compared with proteinase inhibitor activities.

\section{Results}

To explore the role of neutrophil proteinases in acute lung injury, we studied the acid instillation model, 
which is supposed to be neutrophil dependent. We performed unilateral acid instillation (bilateral instillation often leads to immediate death [our unpublished observation]), which produces bilateral, asymmetric neutrophil recruitment and lesions. Neutrophil recruitment into the lung involves adhesion molecules; interestingly, the recruitment of neutrophils is known to be CD11b/CD18 independent in the instilled lung and CD11b/CD18 dependent in the noninstilled lung. CD11b/CD18-dependent neutrophil recruitment has been reported during lipopolysaccharide (LPS)induced acute lung injury. If the mechanisms of recruitment are different, one would expect the neutrophils in the instilled lung to be more active and to secrete larger amounts of proteinases, resulting in asymmetric lesions. Consequently, all these procedures were carried out separately for the left and right lungs to allow a comparison of instilled and noninstilled lungs in each group ( $\mathrm{HCl}$, LPS, control).

In the first part of the study, the effect of alveolar instillations of hydrochloric acid, lipopolysaccharide, and saline were evaluated 6 hours after the challenge in terms of neutrophil recruitment, alveolar neutrophil elastase and gelatinase content, and severity indices (wet-to-dry weight lung ratio and total protein concentration in BAL).

\section{Wet-to-Dry Weight Lung Ratios}

In the $\mathrm{HCl}$ group, the wet-to-dry weight ratio of the instilled lungs was significantly greater than that of the noninstilled lungs and was also greater than the wetto-dry weight ratios of the instilled lungs in the other two groups (control and LPS). The wet-to-dry weight ratios were similar in the LPS and control groups, for both the instilled and the noninstilled lungs (Fig. 1A).

\section{Total Protein Concentration in BAL Fluid}

Total protein concentration in BAL fluid from the $\mathrm{HCl}$-instilled lungs was significantly higher than the protein concentration in BAL fluid from the control and LPS-instilled lungs. Protein concentration in BAL fluid from the noninstilled lungs in the $\mathrm{HCl}$ group was also significantly increased as compared with the noninstilled lungs in the control group. There were no differences between the LPS and control groups for either the instilled or the noninstilled lungs (Fig. 1B).

\section{Myeloperoxidases in Lung Homogenates}

In the $\mathrm{HCl}$ group, myeloperoxidase activities were significantly greater in the instilled than in the noninstilled lungs. Myeloperoxidase activities were significantly greater in the instilled lung from the LPS group than in the instilled lungs of the control group (Fig. 2A).

\section{Neutrophils in BAL Fluid}

Neutrophil counts in BAL fluid from the $\mathrm{HCl}$-instilled and LPS-instilled lungs were significantly increased as compared with the instilled lungs in the control group. Also, neutrophil counts in BAL fluid were higher for the
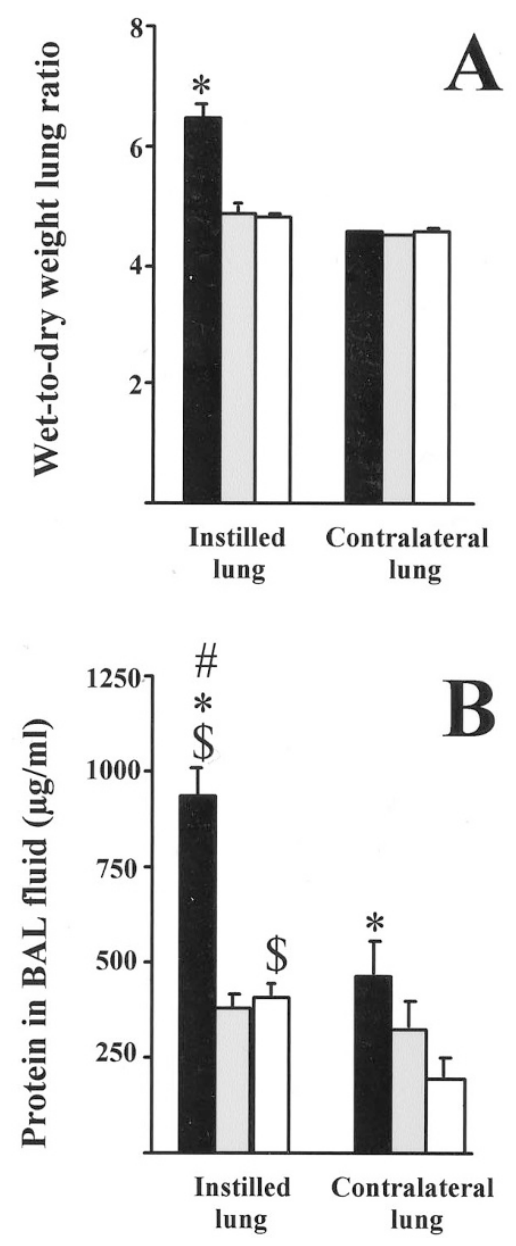

Figure 1.

Indices of injury. A, Wet-to-dry weight ratios of the instilled versus the noninstilled lungs in the three groups (closed bars: hydrochloric acid [HCl] instillation; shaded bars: endotoxin [lipopolysaccharide; LPS] instillation; open bars: control, ie, saline instillation). Wet-to-dry weight ratios were significantly higher for the $\mathrm{HCl}$-instilled lungs than for the other groups $\left({ }^{*} p<0.05\right)$. Wet-to-dry weight ratios of $\mathrm{HCl}$-noninstilled lungs and of LPS-instilled and -noninstilled lungs were not higher than those in the control group ( $n=6$ for the $\mathrm{HCl}$ and control groups, $n=4$ for the LPS group). B, Proteins in bronchoalveolar lavage (BAL) fluid were measured using the Bradford protein assay. Total protein concentration was significantly higher in $\mathrm{HCl}$-instilled and -noninstilled lungs than in control instilled and noninstilled lungs (closed bars: $\mathrm{HCl}$ instillation; shaded bars: LPS instillation; open bars: control, ie, saline instillation). Protein concentrations in BAL fluids from LPS-instilled and -noninstilled lungs were not higher than in those from control instilled and noninstilled lungs ( $n=7$ for the $\mathrm{HCl}$ and control groups, $n=5$ for the LPS group). ${ }^{*} p<0.05$ versus the control condition; $\$ p<0.05$ versus the noninstilled lungs; \#p<0.05 versus the LPS-instilled lungs.

instilled than for the noninstilled lungs in both the $\mathrm{HCl}$ and the LPS groups (Fig. 2B).

\section{Elastase and Gelatinase B Content of Alveolar Neutrophils}

There were no statistically significant differences among the groups regarding the alveolar neutrophil contents of elastase or gelatinase B (Fig. 3).

\section{BAL Proteinase Activities}

Gelatin-zymography of BAL fluids and lung homogenates demonstrated gelatinolytic activities (Fig. 4) that 

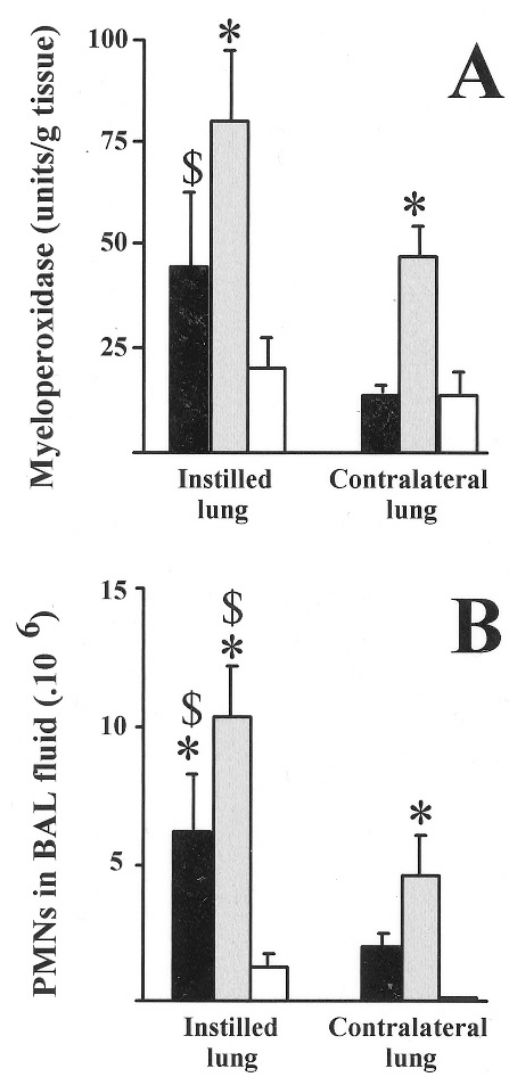

Figure 2.

Neutrophil recruitment. A, Myeloperoxidase activity (U/gm tissue) was significantly higher in LPS-instilled and -noninstilled lungs than in control instilled and noninstilled lungs (closed bars: $\mathrm{HCl}$ instillation; shaded bars: LPS instillation; open bars: control, ie, saline instillation). Myeloperoxidase in $\mathrm{HCl}$-instilled lungs tended to be higher than in control instilled lungs, but the difference did not reach statistical significance. Myeloperoxidase was significantly higher in $\mathrm{HCl}$-instilled lungs than in $\mathrm{HCl}$-noninstilled lungs $(n=6$ for the $\mathrm{HCl}$ and control groups, $n=4$ for the LPS group). ${ }^{\star} p<0.05, \$ p<0.05$ versus the noninstilled lungs. B, Polymorphonuclear leukocyte (PMN) counts were significantly higher in BAL fluids from $\mathrm{HCl}$ - and LPS-instilled lungs than in those from control instilled lungs or from noninstilled lungs. PMN counts in BAL fluids from LPS-noninstilled lungs were significantly higher than in those from control noninstilled lungs ( $n=7$ for the $\mathrm{HCl}$ and control groups; $n=5$ for the LPS group). Closed bars: HCl instillation; shaded bars: LPS; open bars: control, ie, saline instillation; ${ }^{*} p<0.05$ versus the control condition; $\$ p<$ 0.05 versus the noninstilled lungs.

were abolished by $10 \mathrm{~mm}$ of EDTA (metalloproteinase inhibitor) (data not shown). Thus, these gelatinolytic activities are consistent with the presence of gelatinase $A$ and $B$ into both BAL fluids and tissues.

No free gelatinolytic activity was demonstrated in BAL fluids from any of the groups when gelatin was used as the substrate (data not shown). Neither was any free elastolytic activity demonstrated in BAL fluids from any of the groups when MEOSAAPVNA was used as a synthetic substrate (data not shown).

\section{In Situ Zymography}

Diffuse gelatinolytic activities were demonstrated along most lung structures in normal lungs (Fig. 5). These activities were more pronounced in the bronchial and vessel walls than in the alveoli. Some of the intra-alveolar cells also exhibited gelatinolytic activity.
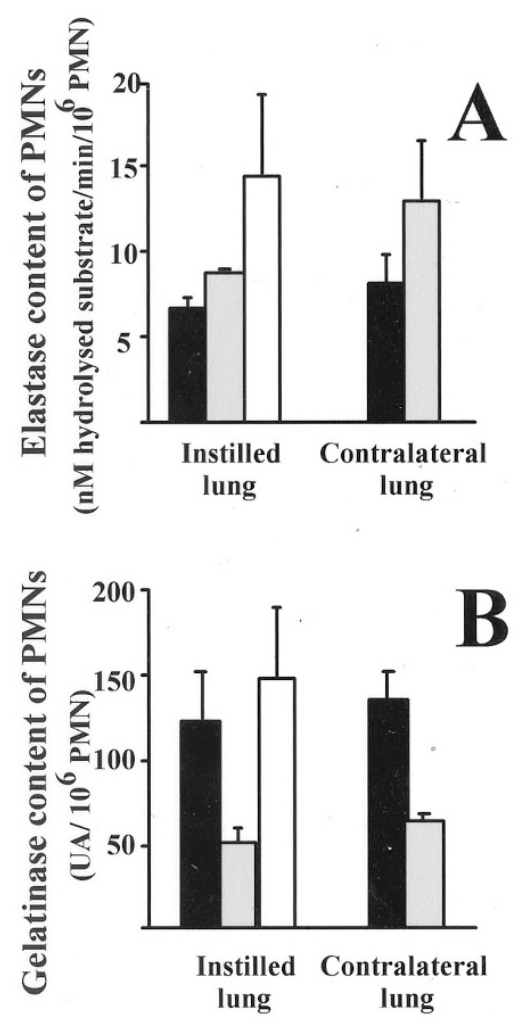

Figure 3.

Proteinase content of alveolar neutrophils. A, The elastase content of alveolar neutrophils (PMNs) (nM hydrolyzed substrate/minute/10 $\mathrm{PMN}$ ) was assessed using a specific synthetic substrate (MEOSAAPVNA) (see "Materials and Methods"). Results for control noninstilled lungs are not shown because BAL fluid PMN counts in this group were not high enough to allow detection of significant substrate degradation. No significant differences were demonstrated between any group pairs (closed bars: $\mathrm{HCl}$ instillation; shaded bars: LPS instillation; open bars: control, ie, saline instillation). In particular, the PMN elastase content was similar for $\mathrm{HCl}$-instilled and LPS-instilled lungs ( $n$ $=7$ for the $\mathrm{HCl}$ and control groups, $n=5$ for the LPS group). B, The gelatinase content of alveolar neutrophils (PMNs) (arbitrary units/10 $\mathrm{PMN}$ ) was assessed using gelatin zymography (see "Materials and Methods"). Results for control noninstilled lungs are not shown because alveolar PMN counts in this group were too low. No significant differences were noted between any group pairs (closed bars: $\mathrm{HCl}$ instillation; shaded bars: LPS instillation; open bars: control, ie, saline instillation). Alveolar PMN gelatinase content was higher in HCl-instilled lungs than in LPS-instilled lungs, but the difference was not significant ( $n=7$ for the $\mathrm{HCl}$ and control groups, $n=5$ for the LPS group).

Gelatinolytic activities decreased when the temperature or duration of the experiment was decreased (data not shown) or when a specific matrix metalloproteinase inhibitor was added (BB-3103) (Fig. 5). Interestingly, both the $\mathrm{HCl}$ - and the LPS-injured lungs showed considerably lower levels of gelatinolytic activity, with almost no activity in alveolar walls after 24 hours of incubation (Fig. 6; all lung samples were analyzed in a blind manner by two investigators). The quantitative analysis of in situ zymography slides confirmed the significant $(p<0.01)$ decrease in gelatinolytic activities in $\mathrm{HCl}$ - and LPS-injured lungs as compared with control lungs: control lungs $100 \pm 7 \%$ ( $n=6$ rats) versus $\mathrm{HCl}$ injury $33 \pm 11 \%$ ( $n=6$ rats) versus LPS injury $40 \pm 12 \%$ ( $n=4$ rats). There was no significant difference between the two injuries. 


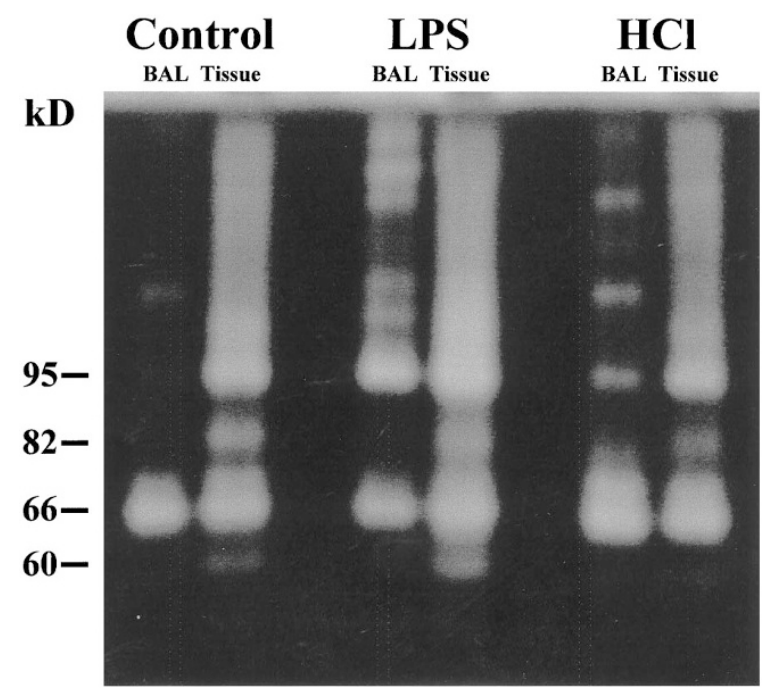

Figure 4.

Gelatin-zymography of lung homogenates and BAL fluids. Zymography was performed under nonreducing conditions in sodium dodecyl sulfate-8\% polyacrylamide gels impregnated with gelatin $(1 \mathrm{mg} / \mathrm{ml})$. Lung homogenate samples ("tissue" lanes) (diluted $\times 10$ in distilled water) and bronchoalveolar lavage fluids ("BAL" lanes) of saline- (control), LPS-, and HCl-instilled rats were evaluated. After electrophoresis, gels were washed and incubated at $37^{\circ} \mathrm{C}$ for 24 hours. Gelatinolytic activities were demonstrated. These gelatinoIytic activities were consistent with the presence of gelatinase A (proform 66 $\mathrm{kd}$ and activated form $60 \mathrm{kd}$ ) and B (proform $95 \mathrm{kd}$ and activated form $82 \mathrm{kd}$ ), respectively. Activated forms of both gelatinase A and B were absent in bronchoalveolar lavage fluids.

\section{Immunohistochemistry of Gelatinase A}

The immunoreactivity for gelatinase A was widely distributed in normal lung, involving the alveolar capillary wall cells. By contrast, intra-alveolar cells (neutrophils) were unreactive (Fig. 7, A to C).

\section{Immunohistochemistry of Rat Tissue Inhibitor of Matrix Metalloproteinase 1 (TIMP-1)}

The immunoreactivity for rat TIMP-1 was weakly distributed in all lung structures in normal lung (Fig. 7E). In $\mathrm{HCl}$-injured lung, the immunoreactivity for TIMP-1 depicted a similar distribution but was increased, especially in alveolar capillary walls (Fig. 7F).

\section{IL-6 and TNF- $\alpha$ Concentrations in Lung Homogenates}

IL-6 is one of the cytokines involved in pro/antiinflammatory response after acute lung injury and has been previously shown to up-regulate antiproteinases, such as TIMP-1. IL-6 concentration in lung homogenates of instilled lungs was significantly increased after both $\mathrm{HCl}$ instillation (15.0 $\pm 1.8 \mathrm{ng} / \mathrm{gm} ; n=6)$ and LPS instillation (12.3 $\pm 1.7 \mathrm{ng} / \mathrm{gm} ; n=4) \mathrm{com}-$ pared with saline-instilled lungs $(0.9 \pm 0.1 \mathrm{ng} / \mathrm{gm} ; n=$ $6 ; p<0.01)$.

Since TNF- $\alpha$ has been shown to increase alveolar capillary wall permeability, its concentration was assessed in lung tissue. TNF- $\alpha$ concentration in lung homogenates of instilled lungs was significantly $(p<$ $0.05)$ increased after LPS instillation $(6.2 \pm 2.1 \mathrm{ng} / \mathrm{gm}$,
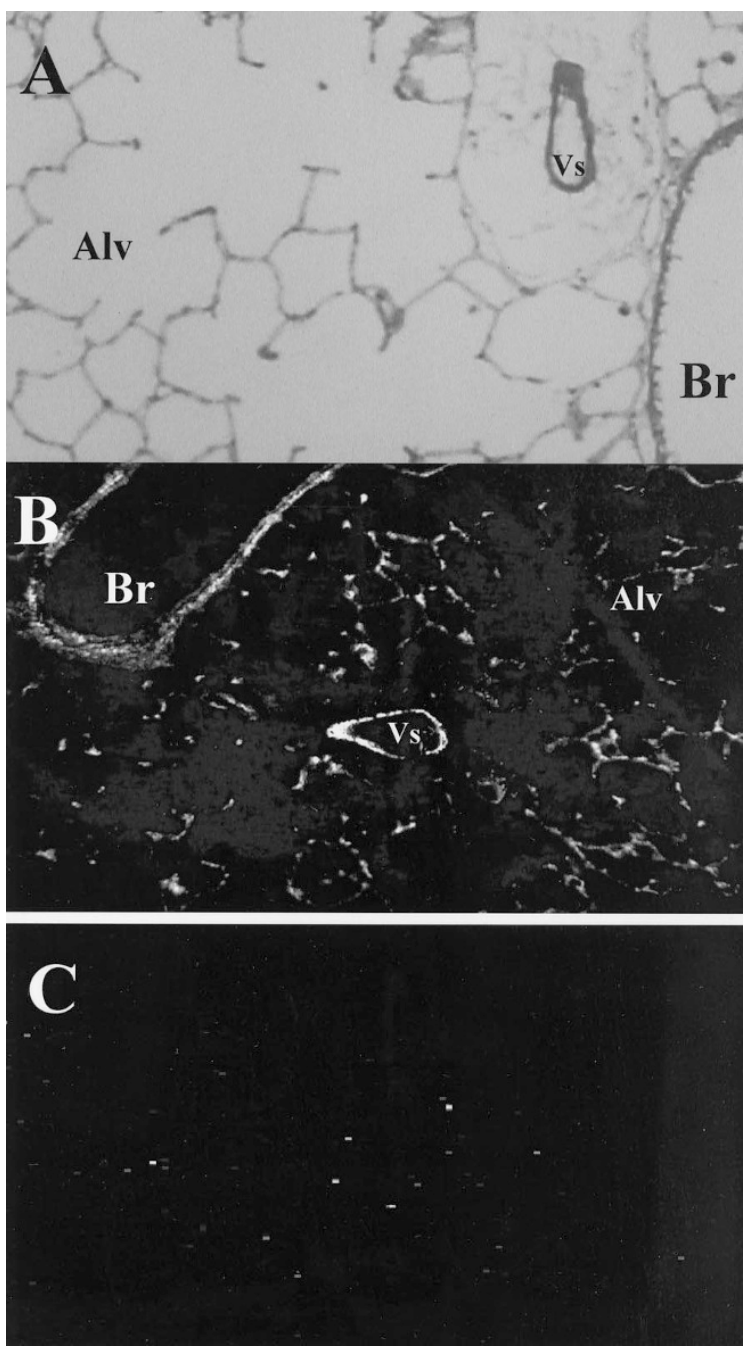

Figure 5.

In situ zymography of control lungs. The 8- $\mu \mathrm{m}$ cryostat sections of $\mathrm{HCl}, \mathrm{LPS}$, and control lungs on glass slides, stored at $-80^{\circ} \mathrm{C}$, were thawed and rinsed for 30 minutes in PBS. They were then dried, and a plastic well was stuck on each section. A fixed volume of photographic emulsion was deposited in each well, and tissue sections were incubated at $37^{\circ} \mathrm{C}$ for 24 hours. At the end of the incubation, the slides were processed by photographic development using D19 developer (Kodak). Tissue sections were examined under a microscope in transmitted light. The background of these specimens appears black due to exposure of the emulsion to ambient light during incubation and processing. Lysis of gelatin in the emulsion produces transparent spots on the slides. In situ zymography of control lungs (B) demonstrated diffuse gelatinolytic activities underlining almost all lung structures. Activities were more pronounced in bronchial $(B r)$ and vessel walls $(V s)$ than in alveoli $(A / v)$, consistent with the fact that activities demonstrated by gelatin-zymography were higher for endothelial and bronchial epithelial cell culture supernatants than for alveolar type II cell supernatants (our unpublished data; and d'Ortho et al, 1997; Yao et al, 1996). The gelatinolytic activity in normal control lungs was almost abolished by addition of $10^{-6} \mathrm{M} \mathrm{BB}-3103$ (a synthetic matrix metalloproteinase inhibitor) to the PBS and to the photographic emulsion (C), as compared with activity without inhibitor (B). A, A slide stained with hematoxylin-eosin; similar magnifications $(\times 150)$ were used for all panels.

$n=4)$ compared with $\mathrm{HCl}$-instilled $(0.4 \pm 0.1 \mathrm{ng} / \mathrm{g}, n$

$=6)$ and saline-instilled lungs (0.3 $\pm 0.1 \mathrm{ng} / \mathrm{g}, n=6)$.

\section{Effect of an Elastase Inhibitor}

In this second set of experiments, the effects of EPI-hNE-4 (elastase inhibitor) and adenovirus (Ad)- 

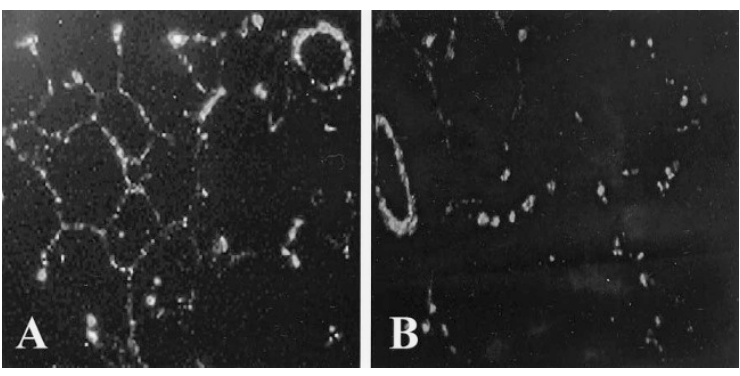

Figure 6.

Comparison of in situ zymography of control and injured lungs. Gelatinolytic activities of control and injured lungs were compared in a blind manner by two investigators (AVdL, CD2) and were found to be consistently decreased in HCL-injured (B) and in LPS-injured (data not shown) lungs, as compared with saline-instilled control lungs $(A)$. Magnification, $\times 400$.

mediated gene transfer (see above), to induce lung overexpression of human TIMP-1, on PMN recruitment and severity indices were assessed in the $\mathrm{HCl}$ model.

The control animals received the vehicle used for the intravenous EPI-hNE-4 solution followed by unilateral lung instillation of $\mathrm{HCl}$. The EPI-hNE-4 animals received intravenous EPI-hNE-4 followed by an $\mathrm{HCl}$ instillation. Six hours later, parameters of injury were assessed.

Rats instilled with hydrochloric acid and given the synthetic leukocyte elastase inhibitor EPI-hNE-4 had significantly lower BAL fluid PMN counts than rats instilled with hydrochloric acid and given the vehicle. However, neither the wet-to-dry weight lung ratio and nor the BAL fluid total protein concentration were significantly different between $\mathrm{HCl}$-instilled rats that had and had not received the elastase inhibitor (Fig. 8).

\section{Effect of Ad.hTIMP-1 Gene Transfer}

Rats were treated 5 days before unilateral lung instillation of $\mathrm{HCl}$ with an intratracheal dose (bilateral instillation) of either a recombinant adenovirus coding for human TIMP-1 or an adenovirus with an empty expression cassette. Six hours after $\mathrm{HCl}$ instillation, the rats were evaluated as described for elastase inhibitor experiments.

Lung overexpression of hTIMP-1 achieved before $\mathrm{HCl}$ instillation did not afford any significant effect regarding neutrophil recruitment or permeability measurements (wet-to-dry weight lung ratio and BAL fluid total protein concentration) (Fig. 9).

\section{Discussion}

The permeability of the alveolar-capillary barrier to proteins is based primarily on the tightness of the alveolar epithelium (Taylor and Gaar, 1970; Wangensteen et al, 1969), which seems less resistant to proteinases than to oxidants (Simon et al, 1986). Thus, possible neutrophil involvement in the injury process may be mediated by proteinases. Elastase and gelatinase act together to enable PMN migration across the basement membrane (Delclaux et al, 1996) and could theoretically play a role in the pathophysiology of ARDS as a result of their ability to degrade extracellular matrix components and to induce epithelial shedding (Delclaux et al, 1997a; Lee et al, 1981; McGuire et al, 1982; Torii et al, 1997; Weiland et al, 1986; Wewers et al, 1988).

\section{LPS Instillation Induces PMN Recruitment Without Marked Permeability Changes}

Based on the results obtained with the LPS model, we can conclude that PMN recruitment is not necessarily associated with a permeability change in vivo. A similar conclusion has been previously made both in human and animal settings (Delclaux et al, 1997b; Martin et al, 1989); moreover, PMN emigration in vitro does not necessarily induce a permeability change of either the endothelial or the epithelial barrier (Parsons et al, 1987).

\section{A Similar Degree of PMN Recruitment and Proteinase Exocytosis Is Observed in the Two Models}

$\mathrm{HCl}$ and LPS challenge induced a similar level of PMN influx into both lung tissue and airspaces, whereas a protein-rich edema was observed only after $\mathrm{HCl}$ induced injury. However, despite an equivalent influx, the neutrophil activation could have been different in term of protease exocytosis, leading to different degrees of injury. Along this line, mechanisms of PMN emigration differ in the two models. In the acidinduced injury model, the recruitment of PMNs is known to be CD11b/CD18 independent in the instilled lung and CD11b/CD18 dependent in the noninstilled lung (Motosugi et al, 1998). CD11b/CD18-dependent PMN recruitment has been reported during LPSinduced acute lung injury (Motosugi et al, 1998). If $\mathrm{PMN}$ is responsible for edema formation, and because the mechanisms of recruitment are different, one would expect the PMNs in the instilled lung to be more active and to secrete larger amounts of proteinases, resulting in asymmetric lesions. Interestingly, we found that ex vivo elastase and gelatinase contents were similar in the $\mathrm{HCl}$ and LPS models, irrespective of the degree of injury. Thus, although we found differences in the degree of the permeability increase, we were unable to demonstrate differences in the level of proteinase exocytosis, suggesting that the level of PMN activation was similar irrespective of the mechanism of recruitment, a finding that is in accordance with our previously published study (Delclaux et al, 1997b). Thus, neutrophil emigration is achieved with a similar degree of protease exocytosis in the two models, resulting in a similar degree of CD11b expression in both CD11b/CD18-independent and -dependent models of lung injury as previously described (Motosugi et al, 1998).

\section{The Two Models Are Characterized by an Excess of Proteinase Inhibitors 6 Hours After the Challenge}

We initially thought that the injury process might result from a proteinase/inhibitor imbalance in favor of pro- 

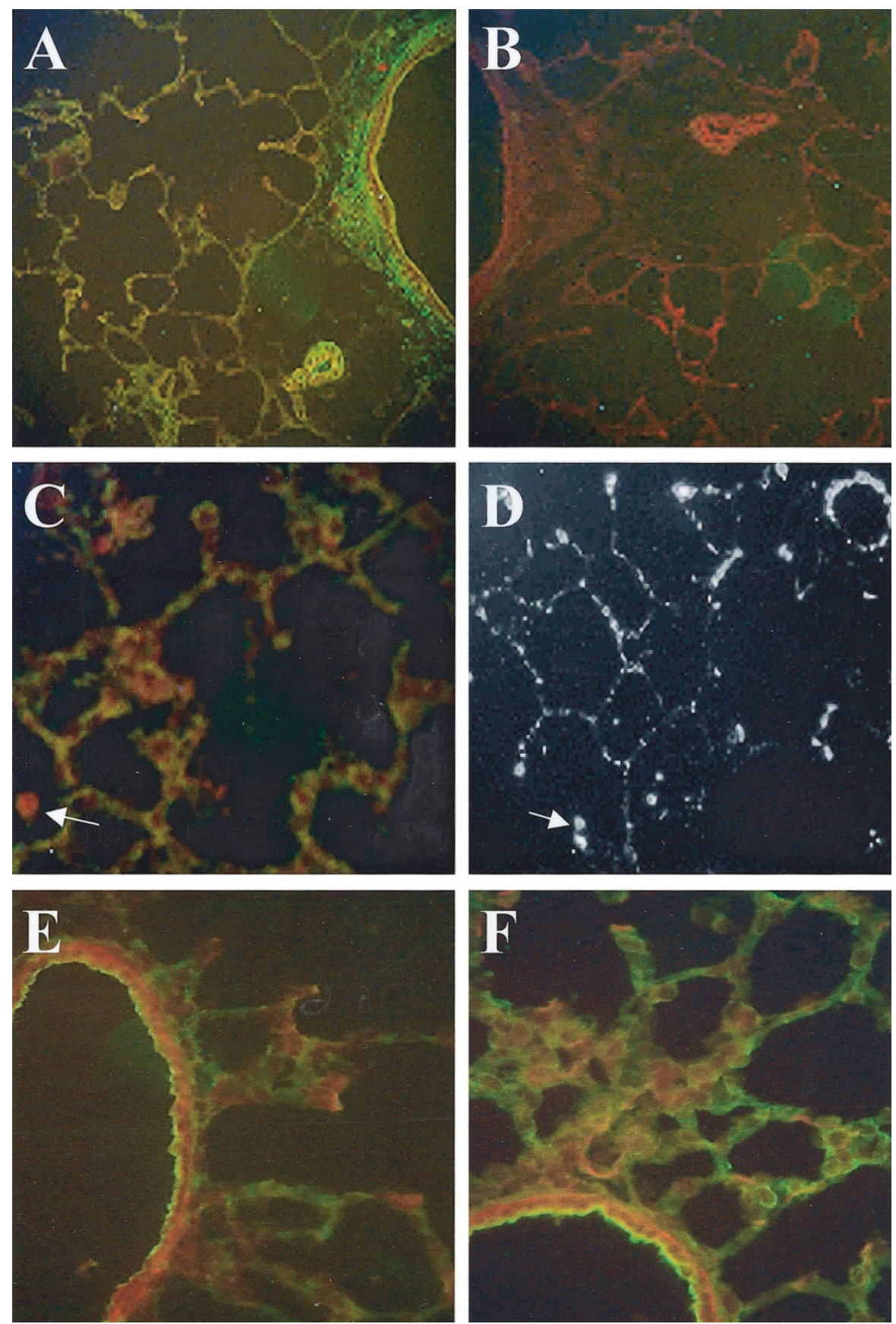

Figure 7.

Immunohistochemistry of gelatinase A and TIMP-1. Immunolocalization of gelatinase A (see "Materials and Methods") demonstrated diffuse expression of gelatinase $A$ in control lungs ( $A$ and $C$ : green fluorescence) that matched the image provided by in situ zymography (D). B, A negative control done using nonrelevant rabbit antibody to human thyroglobulin. The open arrow shows an inflammatory cell into alveolar space, which stained negatively for gelatinase A, thus constituting an internal negative control. Bronchial and vessel walls seem to present a higher fluorescence intensity than alveolar structures, that paralleled in situ zymography data. Magnification for A and B, $\times 150$; for C-F, $\times 400$. Immunolocalization of TIMP-1 (see "Materials and Methods") demonstrated a weak expression of TIMP-1 in control lungs (E: green fluorescence). In HCl-instilled lung, immunoreactivity was increased (F); similar findings were obtained with LPS-instilled lungs (data not shown). The negative control was obtained using nonrelevant rabbit antibody to human thyroglobulin showed similar results as B (data not shown).

teinase. However, we found no excess proteinase release in the alveolar spaces. We therefore looked for evidence of antiproteinase deficiency. BAL fluids contained no free elastolytic or gelatinolytic activity, indicating that antiproteinase activity was adequate in the alveolar compartment. However, data on the alveolar compartment do not necessarily reflect what is happening in the lung tissue, ie, at the site of the lung injury. This prompted us to look for proteinase activity within the interstitial compartment using in situ zymography.

In situ zymography was used on vascular tissue (Galis et al, 1994), then on lung tissue in a study by Pardo et al (1996) that found no gelatinolytic activity in normal lung tissue. In preliminary experiments, we found that gelatinolytic activities were detectable as 

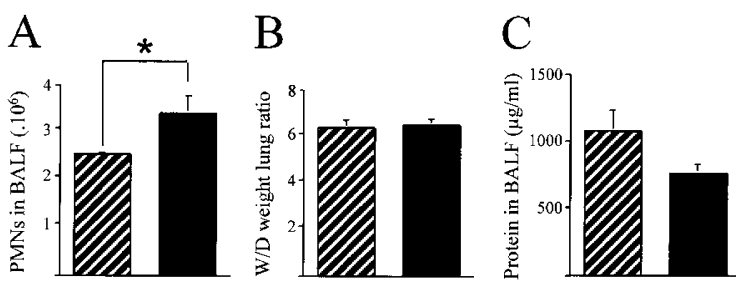

\section{Figure 8.}

Effect of neutrophil recruitment inhibition. The effects of intravenous EPIhNE-4 (a synthetic leukocyte elastase inhibitor) on PMN recruitment and severity indices in the $\mathrm{HCl}$-instilled lungs were assessed. The black bars represent the $\mathrm{HCl}$-instilled lungs of rats given intravenous vehicle and the hatched bars represent the $\mathrm{HCl}$-instilled lungs of rats given intravenous EPI-hNE-4. A, BAL fluid PMN counts in the EPI-hNE-4 and control groups $\left(.10^{6}\right)$. BAL fluid PMN counts in $\mathrm{HCl}$-instilled lungs were significantly lower in the EPI-hNE-4 group than in the control group ( $n=5$ for each group). ${ }^{*} p<$ 0.05. B, Wet-to-dry weight ratios of $\mathrm{HCl}$-instilled lungs in the EPI-hNE-4 and control groups were similar ( $n=4$ for each group). C, BAL fluid total protein concentration in $\mathrm{HCl}$-instilled lungs was higher in the EPI-hNE-4 group than in the control groups, but the difference was not significant $(n=4$ for each group). BALF $=$ BAL fluid.
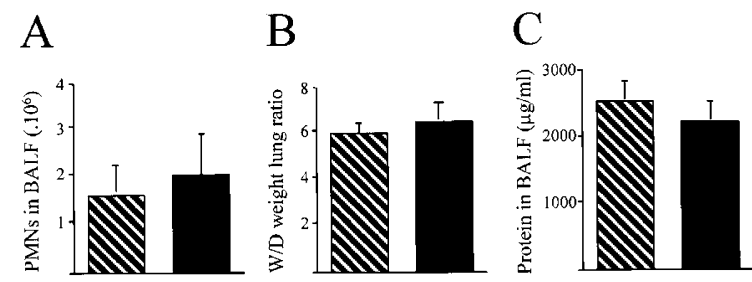

\section{Figure 9.}

Effect of adenovirus (Ad)-mediated gene transfer to induce overexpression of human TIMP-1 (hTIMP-1). The effects of Ad.hTIMP-1 gene transfer on neutrophil recruitment and severity indices in the $\mathrm{HCl}$-instilled lungs were assessed. Rats were instilled (into both lungs) 5 days before unilateral $\mathrm{HCl}$ instillation with a single dose of either a recombinant adenovirus coding for human TIMP-1 ( $10^{8}$ plaque-forming units [pfu] Ad.hTIMP-1) or an adenovirus with an empty expression cassette $\left(10^{8}\right.$ pfu Ad.Null) (see "Materials and Methods"). Efficiency of gene transfer to the lung was assessed by ELISA detection of hTIMP-1 on BAL fluid samples. BAL was performed 6 hours after $\mathrm{HCl}$ instillation as described in "Materials and Methods." The BAL fluid concentration of hTIMP-1 was $44 \pm 15 \mathrm{ng} / \mathrm{ml}$ in the Ad.hTIMP-1 group and was not detectable $(<10 \mathrm{ng} / \mathrm{ml})$ in the Ad-Null group ( $n=5$ for each group). The black bars represent the $\mathrm{HCl}$-instilled lungs of rats given Ad-Null and the hatched bars represent the $\mathrm{HCl}$-instilled lungs of rats given Ad.hTIMP-1. A, BAL fluid PMN counts $\left(.10^{6}\right)$; B, wet-to-dry weight ratios; and C, BAL fluid total protein concentration of $\mathrm{HCl}$-instilled lungs in the Ad.hTIMP-1 and Ad-Null groups. No difference between Ad.hTIMP-1 and Ad-Null groups was evidenced concerning any marker of injury ( $n=5$ for each group). W/D = wet-to-dry.

early as the sixth hour in the bronchi and vessels of normal lungs. Inhibition of the activities was achieved by incubation at $4^{\circ} \mathrm{C}$ or in the presence of BB-3103 (matrix metalloproteinase inhibitor), confirming that proteinase(s) and metalloproteinases were responsible for the gelatin lysis. Gelatin zymography of lung homogenates confirmed the presence of both gelatinase $A$ and gelatinase $B$, as previously demonstrated (Pardo et al, 1996).

We found that gelatinolytic activities were detectable in all the structures of normal lungs at 24 hours, namely the alveolar-capillary wall, the bronchial tree, and the vessels. This result is in keeping with the fact that bronchial epithelial cells and endothelial cells constitutively express gelatinase(s) involved in basement membrane turnover (Partridge et al, 1993; Yao et al, 1996). Furthermore we have recently shown, using in vitro experiments, that type 2 alveolar epithelial cells at confluence, which have been shown to constitutively secrete a gelatinase A (d'Ortho et al, 1997), were responsible for spontaneous matrix degradation (Lacherade et al, 2001). In accordance with the findings of Hayashi et al (1996), immunolocalization of gelatinase A showed a diffuse pattern of expression in lung tissue that was fully consistent with the in situ zymography data. These findings, together with those obtained in vitro with A549 alveolar epithelial cells previously described (Lacherade et al, 2001), demonstrate that basal gelatinase $\mathrm{A}$ expression is probably responsible for the physiologic turnover of the basement membrane and explain the diffuse gelatinolytic activities evidenced using in situ zymography.

In $\mathrm{HCl}$ - and LPS-injured lungs, in situ zymography showed marked decreases in gelatinolytic activities, ruling out the hypothesis of an antiproteinase deficiency. It can be concluded that 6 hours after the intratracheal challenge, an excess of antiproteinases rather than an excess of proteinases seems to exist in lung tissue and airspaces. Nevertheless, an earlier excess of proteinases compared with their inhibitors cannot be ruled out by these single time point experiments.

The gelatinolytic activity decreases demonstrated by in situ zymography in our study may be ascribable to an increase in antiproteinase activity. Such a phenomenon has been observed in ARDS, which is characterized by an antiproteinase excess (rather than a proteinase excess) leading to an absence of elastase and gelatinase activities in the alveolar spaces when the syndrome is established (Delclaux et al, 1997a; Idell et al, 1985; Weiland et al, 1986; Wewers et al, 1988). At least two mechanisms could theoretically lead to an increase in antiproteinase activity: increased endothelial permeability may have allowed serum inhibitors, namely TIMP and $\alpha 2$-macroglobulin, to gain access to the interstitial gelatinases and/or local inhibitor synthesis may have been up-regulated by proinflammatory cytokines. In vitro studies have demonstrated that leukocyte elastase inhibitors are up-regulated in alveolar type 2 cells by inflammatory cytokines (Sallenave et al, 1994), and in a recent study we demonstrated that TNF- $\alpha$ does not augment the gelatinase activity secreted by alveolar type 2 cells because up-regulation of both gelatinase $B$ and TIMP-1 occurs concomitantly (Lacherade et al, 2001). Piedboeuf and colleagues (1994) reported that increased TIMP-1 expression occurred within 1 hour of oleic acid administration in foci of inflammation; recently, Gipson et al (1999) demonstrated a rapid increase of both TIMP-2 (0.5 to 4 hours) and secretory leukocyte proteinase inhibitor (1 to 8 hours) mRNAs in IgG immune complex-induced lung injury. Whether this up-regulation of proteinase inhibitors is sufficient to counterbalance the proteinase effect remains under debate. However, a decrease in proteinase activities is in agreement with the occurrence of a fibroproliferative process in this acid-induced injury model (Yano et al, 1996) and during ARDS (Clark et al, 1995). 


\section{Increased IL-6 Concentration in Lung Tissue Could Be Responsible for Local TIMP-1 Up-Regulation}

Since in situ zymography assays suggested an excess of inhibitors over proteinases, we evaluated the presence of TIMP-1 in lung tissue. Immunocytochemistry results suggest an up-regulation of TIMP-1 in lung tissue. In further exploring the mechanisms of this up-regulation, an increase in IL-6 concentration in lung homogenates was evidenced compared with normal lung whether the mechanism of injury was $\mathrm{HCl}$ or LPS. IL-6 was assessed because this cytokine is known to (a) be up-regulated during acute lung injury and (b) up-regulate TIMP-1 synthesis (Lotz and Guerne, 1991). Moreover, the significant increase in TIMP-1 after both $\mathrm{HCl}$ and LPS instillation helps to understand the similar decrease of gelatinolytic activities suggested by in situ zymography.

\section{Inhibition of HCl-Induced PMN Recruitment Does Not Modify the Permeability Changes}

Since these single time point experiments cannot definitely rule out earlier proteinase excess, inhibition of proteinase activity was realized concomitantly with the acid instillation. Because elastase is involved in PMN transmigration across basement membrane in vitro (Delclaux et al, 1996), we used a potent synthetic inhibitor of human neutrophil elastase, EPI-hNE-4. Rats pretreated with intravenous EPI-hNE-4 exhibited a significant decrease in BAL fluid alveolar neutrophil counts. However, this decrease in PMN recruitment was not associated with modifications in severity indices in the $\mathrm{HCl}$ model, namely the wet-to-dry weight ratio or the total protein concentration in BAL fluid. Thus, the increased alveolar-capillary permeability induced by $\mathrm{HCl}$ instillation was not improved by inhibiting leukocyte elastase activity, arguing against a predominant role of PMNs in this model. This conclusion is at variance with previous results obtained by others (Folkesson et al, 1995; Goldman et al, 1992; Knight et al, 1992), however, these discrepancies could be partly justified by species-related characteristics (rat versus rabbit). Furthermore, Nagase and colleagues (1999) have recently shown that plateletactivating factor mediates acid-induced lung injury in genetically engineered mice without affecting the efficiency of PMN sequestration. Thus, these authors have clearly demonstrated that edema formation due to acid instillation is independent of PMN recruitment in mice.

\section{Adenovirus-Mediated Gene Transfer to Induce Overexpression of Human TIMP-1 Does Not Modify the Permeability Changes}

To definitively rule out the participation of matrix metalloproteinases in the injury process, lung overexpression of human TIMP-1, obtained by gene transfer, was realized before the onset of $\mathrm{HCl}$-induced injury. TIMP-1 overexpression did not afford any protection regarding either neutrophil influx or permeability changes. Importantly, human TIMP-1 overexpression in rats has been recently demonstrated to cause local decrease in gelatinolytic activities, supporting the inhibitory efficiency of human TIMP-1 in rat lung (Vieillard-Baron et al, 2000).

The absence of permeability changes in this model are in agreement with our recent findings demonstrating that gelatinase $B$ does not contribute to the TNF- $\alpha$-induced increase of epithelial permeability in vitro (Lacherade et al, 2001). On the other hand, the absence of inhibition of neutrophil influx evidenced despite TIMP-1 overexpression could seem in disagreement with our previous findings, because we demonstrated that gelatinase $B$ participates in neutrophil migration in vitro (Delclaux et al, 1996). However, the role of gelatinase $B$ in neutrophil migration is still a matter of debate. Our in vitro findings were obtained with human neutrophils, and a recent study, using gelatinase B-deficient mice, support the hypothesis that gelatinase $B$ could participate in neutrophil migration essentially in young animals (D'Haese et al, 2000).

\section{Increased Permeability of Alveolar Capillary Wall Barrier Is Not Due To an Increase in Lung TNF-a Secretion}

Since TNF- $\alpha$ has been shown to increase alveolar capillary wall permeability independent of neutrophils, both in vivo and in vitro (Horvath et al, 1988; Lacherade et al, 2001), its concentration in lung tissue was assessed. Despite the increased edema in $\mathrm{HCl}-$ induced injury, no significant increase in TNF- $\alpha$ concentration was demonstrated; however, this result does not rule out the fact that this cytokine could have been involved, as recently demonstrated by Davidson et al (1999). Nevertheless, $\mathrm{HCl}$ may have induced chemical injury of lung tissue; and subsequent inflammatory events linked to the increased permeability warrant further investigations.

In conclusion, as observed in vitro, PMN emigration does not necessarily induce edema formation, and $\mathrm{HCl}$-induced protein-rich edema does not seem to be caused by a larger neutrophil proteinase exocytosis or a deficit of antiproteinase defense. The absence of a role for neutrophils in edema formation is consistent with studies demonstrating that (a) a permeability increase occurs before PMN influx in animal models (Li et al, 1995) and after PMN influx in humans (Fowler et al, 1987), (b) alveolar-capillary wall permeability can be increased in vivo in the absence of neutrophils (Horvath et al, 1988), (c) TNF- $\alpha$, a proinflammatory cytokine that plays a key role in the pathophysiology of ARDS, can induce an increase in the permeability to albumin of both endothelial and epithelial monolayers in vitro (Curtis et al, 1998; Li et al, 1995), and (d) ARDS is known to occur in neutropenic patients (Delclaux et al, 1997a).

\section{Material and Methods}

\section{Animal Preparation}

Adult male Sprague-Dawley rats weighing about $250 \mathrm{~g}$ were used (Charles River Laboratories, Saint-AubainLès-Elbeuf, France). The rats were housed in air- 
filtered, temperature-controlled units and were allowed free access to food and water. Unilateral alveolar instillations were performed as previously described (Motosugi et al, 1998). Briefly, the rats were anesthetized using isoflurane (Abbott, France), and the trachea was exposed. A fine-bore polyester cannula (22 gauge, $32 \mathrm{~mm}$; Abbott) introduced into the distal segment of one lung was used to administer one of the solutions (see below). The animals were propped up at $60^{\circ}$ throughout the experiment. The intrabronchial cannula was removed after the instillation, the skin was sutured with clips, and the animals were allowed to awake. Elastase inhibitor was administered by intravenous injection in a tail vein, under isoflurane anesthesia. This animal study has been approved by our Institutional Review Board.

\section{Preparation of Solutions}

Hydrochloric Acid. One-tenth of $1 \mathrm{ml}$ of $33 \% \mathrm{HCl}$ was mixed with $9 \mathrm{ml}$ of sterile pyrogen-free $0.9 \%$ $\mathrm{NaCl}$. The final concentration was $0.1 \mathrm{~N}$.

LPS. LPS $4 \mu \mathrm{g} / \mathrm{ml}$ was diluted in $0.9 \% \mathrm{NaCl}$ (Escherichia coli endotoxin 055:B5 lipopolysaccharide; Sigma, France).

EPI-hNE-4. This human neutrophil elastase inhibitor (kindly provided by Dr. F. Saudubray, Debiopharm S.A., Lausanne, Switzerland) was diluted in a concentration of $10 \mathrm{mg} / \mathrm{ml}$. EPI-hNE-4 inhibitor, a highly specific and potent inhibitor $(6.237 \mathrm{kd})$ of human neutrophil elastase, has been discovered and engineered using the patented phage-display technology (Roberts et al, 1992). It was derived from the second Kunitz-domain of the light chain of its naturally occurring human proteinase inhibitor (inter- $\alpha$ inhibitor). Previous experiments performed our laboratory have demonstrated the potent inhibitory effect of this compound both in vitro and in vivo (C Lafuma, manuscript submitted); EPI-hNE-4 has been shown to inhibit both human (Ki: $\left.4 \cdot 10^{-12} \mathrm{M}\right)$ and rat $\left(\mathrm{Ki}: 10^{-7} \mathrm{M}\right)$ neutrophil elastase (Dr. F. Saudubray, Debiopharm S.A., personal communication, 2000).

\section{Experimental Protocol}

The study was divided in two parts. In the first part, alveolar instillations of hydrochloric acid, lipopolysaccharide, and saline were compared in terms of neutrophil recruitment, alveolar neutrophil elastase and gelatinase content, and severity indices (wet-to-dry weight lung ratio and total protein concentration in $B A L)$. In a second set of experiments, the effects of EPI-hNE-4 (elastase inhibitor) and Ad-mediated gene transfer, to induce lung overexpression of human TIMP-1, on PMN recruitment and severity indices were assessed in the $\mathrm{HCl}$ model.

\section{Part One of the Study}

Three groups of rats were studied. In the first group, animals given an instillation of $1 \mathrm{ml} / \mathrm{kg}$ of $0.9 \% \mathrm{NaCl}$ served as controls. The second and third groups were instilled with $1 \mathrm{ml} / \mathrm{kg}$ of $\mathrm{HCl}$ or LPS solutions. Evans blue dye ( $2 \mathrm{mg} / \mathrm{ml}$; Sigma) was added to all solutions to allow identification of the injured lung segment.

Six hours after the instillation, the rats were anesthetized again, using an intraperitoneal injection of pentobarbital sodium ( $80 \mathrm{mg} / \mathrm{kg}$ ). After exsanguination by transsection of the abdominal aorta, thoracotomy was performed, and the heart and lungs were harvested en bloc. Rats that had both lungs stained blue were excluded. Each group was divided into three subgroups.

A first subgroup of rats was used for wet-to-dry weight lung ratio and myeloperoxidase determination. Each freshly harvested lung was separated in two fragments, of which one was weighed, then dried at $40^{\circ} \mathrm{C}$ for 72 hours and finally weighed again. The wet-to-dry weight ratio was calculated by dividing the wet weight by the dry weight. The second fragment was stored at $-80^{\circ} \mathrm{C}$ and used later for the myeloperoxidase assay.

A second subgroup of rats was used for in situ zymography. Their lungs were insufflated with 50\% Tissuetek-50\% PBS, frozen in liquid nitrogen, and stored at $-80^{\circ} \mathrm{C}$ until they were cut in $8-\mu \mathrm{m}$ cryostat sections for in situ zymography.

In the third subgroup, the right then the left bronchi were clamped. BAL of the left lung, then of the right lung, was performed using a tracheostomy tube. On each side, five $4-\mathrm{ml}$ aliquots of $37^{\circ} \mathrm{C}$, sterile, pyrogenfree, $0.9 \%$ saline were flushed through the tracheostomy tube. The five fractions were recovered and pooled. The total number of cells was counted using a standard hemocytometer. Cytospin preparations were made using a Shandon 3 cytocentrifuge (Shandon, France). The cells were fixed and stained with MayGrünwald Giemsa. Differential counts on 200 cells were done using standard morphologic criteria. The BAL fluid was then centrifuged at $300 \times g$ for 7 minutes. The supernatant was collected, stored at $-80^{\circ} \mathrm{C}$, and used subsequently for total protein concentration and proteinase activity determination. The cell pellet was lysed with $1 \mathrm{ml}$ of $1 \%$ Triton $/ 2.10^{6}$ cells. The lysate was stored at $-80^{\circ} \mathrm{C}$ and used for determination of the total PMN elastase and gelatinase contents.

All these procedures were carried out separately for the left and right lungs to allow a comparison of instilled and noninstilled lungs in each group $(\mathrm{HCl}$, LPS, control).

\section{Part Two of the Study}

Effects of Leukocyte Elastase Inhibitor (EPI-hNE-4) Administration. Two other groups of rats were studied. The control animals received $1 \mathrm{ml} / \mathrm{kg}$ of the vehicle used for the intravenous EPI-hNE-4 solution, followed by unilateral lung instillation of $1 \mathrm{ml} / \mathrm{kg}$ of $\mathrm{HCl}$ at 15 minutes after recovery from the anesthesia. The EPIhNE-4 animals received $1 \mathrm{ml} / \mathrm{kg}$ of intravenous EPIhNE-4 followed by an $\mathrm{HCl}$ instillation. Six hours later, the rats were anesthetized again, by intraperitoneal administration of pentobarbital sodium, and were used for BAL (differential cell count and total protein 
concentration) or determination of the wet-to-dry weight ratio of the instilled lungs.

Effects of Recombinant Adenovirus for the Human TIMP-1 Gene Transfer (Ad.hTIMP-1) in the Rat Lung. Two other groups of rats were studied. In the Ad.hTIMP-1 study, rats were treated 5 days before unilateral lung instillation of $1 \mathrm{ml} / \mathrm{kg}$ of $\mathrm{HCl}$ with a single intratracheal dose of either a recombinant adenovirus coding for human TIMP-1 $\left(10^{8}\right.$ plaque-forming units [pfu] of Ad.hTIMP-1) or an adenovirus with an empty expression cassette $\left(10^{8}\right.$ pfu of Ad.Null), as previously described (Vieillard-Baron et al, 2000). Ad.hTIMP-1 is a replication-deficient recombinant adenovirus serotype 5 vector capable of high-level hTIMP-1 gene expression. Ad.Null was used as the control. Intratracheal instillation of $150 \mu \mathrm{l} / \mathrm{rat}$ of diluted Ad.hTIMP-1 or Ad.Null was performed in both lungs (bilateral instillation) as previously described (VieillardBaron et al, 2000). Six hours after $\mathrm{HCl}$ instillation, the rats were evaluated as described for elastase inhibitor experiments.

A previous study has demonstrated the efficacy of gene transfer to the rat lung after intratracheal Ad.hTIMP-1 instillation, TIMP-1 being expressed into alveoli, and an inhibition of gelatinolytic activities being evidenced by in situ zymography (see above) (Vieillard-Baron et al, 2000). To further assess the efficiency of gene transfer in these experiments, BAL fluid levels of hTIMP-1 protein were measured 6 hours after $\mathrm{HCl}$ instillation ( 5 days after administration of Ad.hTIMP-1 [10 $\left.10^{8} \mathrm{pfu}\right]$ or Ad.Null $\left[10^{8} \mathrm{pfu}\right]$ ). ELISA detection of hTIMP-1 was performed on BAL samples (TIMP-1, human ELISA system, Amersham Pharmacia Biotech, France). The ELISA system used selectively measures hTIMP-1 and does not cross-react with rat TIMP-1 (Vieillard-Baron et al, 2000).

\section{Total Protein Concentration}

Total protein concentration in BAL fluid was determined using the Bradford protein assay with a standard curve for albumin.

\section{Proteinase (Elastase and Gelatinase B) Content of Alveolar Neutrophils}

Because rat leukocyte elastase is closely similar to its human counterpart, cell lysates were assayed using the specific neutrophil elastase substrate methoxysuccinylAla-Ala-Pro-Val paranitroanilide (MEOSAAPVNA, 0.2 $\mathrm{mm}$; Sigma), as described elsewhere (Delclaux et al, 1997b). Results were expressed as nanomoles of peptide hydrolyzed per minute $/ 10^{6}$ PMNs.

Zymography was used to assay rat neutrophil gelatinase B content in cell lysates. Zymography was performed under nonreducing conditions in sodium dodecyl sulfate $8 \%$ polyacrylamide gels impregnated with gelatin (1 mg/ml; Sigma). After electrophoresis, the gels were washed and incubated at $37^{\circ} \mathrm{C}$ for 24 hours. Gelatinolytic activities were determined by scanning densitometry and expressed as arbitrary units, as described previously (Delclaux et al, 1997a). Results were converted to arbitrary units $/ 10^{6} \mathrm{PMNs}$.

\section{BAL Fluid and Lung Homogenate Proteinase Activities}

The presence of gelatinases in alveolar spaces and lung tissue was assessed by gelatin-zymography of BAL fluids and lung homogenates, respectively. Samples were processed in a similar manner as for the neutrophil lysates.

The presence of elastase or gelatinase activity in BAL fluid reflects an excess of proteinases over antiproteinases. Free gelatinolytic activities of BAL fluid were determined on ${ }^{3} \mathrm{H}$-labeled gelatin, as described elsewhere (Delclaux et al, 1997b). Briefly, $100 \mu \mathrm{l}$ of BAL fluid was incubated for 72 hours at $37^{\circ} \mathrm{C}$ with 50 $\mu \mathrm{g}$ of $\left[{ }^{3} \mathrm{H}\right]$ gelatin $\left(500,000\right.$ counts.minute $\left.{ }^{-1} .50 \mu \mathrm{g}^{-1}\right)$ and with either $1 \mathrm{~mm}$ of 4-(2-aminoethyl)-benzenesulfonyl fluoride (AEBSF; Sigma; serine proteinase inhibitor, residual activity due to gelatinase(s)) or $2 \mathrm{~mm}$ of phenanthrolene (Sigma; metalloproteinase inhibitor, residual activity due to serine proteinase(s)). Gelatin degradation was assessed based on the release of trichloroacetic acid-soluble (15\% wt/vol) radioactivity.

Elastase activity was also evaluated in BAL fluid using a specific neutrophil elastase substrate, MEOSAAPVNA (0.2 mm; Sigma), as described elsewhere (Delclaux et al, 1997b).

\section{Myeloperoxidase Assay}

To determine whether alveolar neutrophils contributed the same proportion of total neutrophils sequestered in the lung in the different models, we also assessed myeloperoxidase in lung homogenates as a means of evaluating the total number of PMNs sequestered in the lungs. In preliminary experiments, we checked that almost all neutrophils were retrieved from the airspaces with the BAL procedure used in our study (histologic examination).

A lung tissue specimen was thawed and homogenized in $10 \mathrm{ml} / \mathrm{g}$ of $10 \mathrm{~mm}$ potassium phosphate buffer containing $1 \mathrm{~mm}$ of ethylenediamine tetraacetic acid (PPB, pH 6.0) and 0.5\% hexadecyltrimethylammoniumbromide (Sigma). This suspension was sonicated on ice using a Branson cell disrupter at 65 watt for 30 seconds, then centrifuged at $10,000 \times g$ for 20 minutes at $4^{\circ} \mathrm{C}$. One hundred microliters of supernatant were mixed with $2.9 \mathrm{ml}$ of PPB containing 0.167 $\mathrm{mg} / \mathrm{ml}$ of O-dianisidine hydrochloride (Sigma) and $0.0005 \%$ hydrogen peroxide 30\% (Prolabo, Paris, France). The absorbance change at $460 \mathrm{~nm}$ was measured during 3 minutes at $25^{\circ} \mathrm{C}$, using a spectrophotometer. One unit of myeloperoxidase activity was defined arbitrarily as the amount of enzyme necessary to catalyze an increase in absorbance of 1 per minute at $460 \mathrm{~nm}$ at $25^{\circ} \mathrm{C}$.

\section{In Situ Zymography}

In situ zymography was performed using a method adapted from Galis et al (1994) described below. A photographic emulsion containing gelatin was applied 
to cryostat sections of unfixed tissue. Slides were incubated in humidified atmosphere at $37^{\circ} \mathrm{C}$. After development, the background of these sections appears black as a result of exposure of the emulsion to ambient light during incubation. Lysis of gelatin in the emulsion demonstrates the presence of active gelatinolytic enzymes and is seen as transparent spots on the slides.

In Situ Zymography on Rat Lung Tissue. The 8- $\mu \mathrm{m}$ cryostat sections of $\mathrm{HCl}$, LPS, and control lungs on glass slides, stored at $-80^{\circ} \mathrm{C}$, were thawed and rinsed for 30 minutes in PBS under continuous agitation. They were then dried at ambient temperature, and a plastic well was stuck on each section. A mixture of $10 \mathrm{ml}$ of photographic emulsion NTB-2 (Kodak, France), $20 \mathrm{ml}$ of distilled water, and $0.5 \mathrm{ml}$ of glycerol was stored at $4^{\circ} \mathrm{C}$, then incubated at $37^{\circ} \mathrm{C} 1$ hour before use. The tissue sections were incubated with the emulsion at $37^{\circ} \mathrm{C}$ for various lengths of time $(1,3,6,16,24,48$, and 72 hours) to determine changes in gelatinolytic activities over time. With a fixed volume of substrate, gelatinolytic activities appeared in the alveolar capillary wall of normal control lungs at 24 hours. An experiment involving incubation at $4^{\circ} \mathrm{C}$ was done to test whether cold inhibited detected activities, attesting to their enzymatic character. The inhibitory profile of the enzymatic activities was determined by adding $10^{-3} \mathrm{M}$ of AEBSF, $10^{-3} \mathrm{M}$ of EDTA (Sigma, metalloproteinase inhibitor), $10^{-6} \mathrm{M}$ of BB-3103, or $10^{-5} \mathrm{M}$ of E-64 to the PBS and to the emulsion. At the end of incubation, the slides were processed by photographic development using a D19 developer (Kodak). Tissue sections were examined by two of us (AVdL, CD2) under a microscope in transmitted light, in a blinded fashion. The background of these specimens appears black as a result of exposure of emulsion to ambient light during incubation and processing. Lysis of gelatin in the emulsion produces transparent spots on the slides.

Furthermore, gelatinolytic activities were quantified using image analysis (image analysis program $\mathrm{NIH}$ Image 1.52 Macintosh) to quantify both the surface area and the intensity of lysis bands. Ten squares (side: $500 \mu \mathrm{m}$, magnification $\times 400$ ) in the alveoli area were randomly quantified for each instilled rat lung and expressed as arbitrary units. The arbitrary units obtained from quantification of normal control lung were set as $100 \%$.

\section{Immunocytochemistry}

Antibodies. Specific rabbit polyclonal antibody to human gelatinase A was obtained from Triple Point Biologics (Clinisciences, France); this antibody has been shown to cross-react with the corresponding rat antigen (d'Ortho et al, 1997). Specific goat polyclonal antibody to rat TIMP-1 was obtained from Santa Cruz Biotechnology, Inc. (Santa Cruz, CA). Nonrelevant rabbit antibody to human thyroglobulin (Dako, France) was used as the negative control. The secondary antibody used for immunolocalization was FITCconjugated sheep anti-rabbit immunoglobulin or sheep anti-goat immunoglobulin (Santa Cruz Biotechnology, Inc.), diluted 1:500 and 1:200, respectively.

Immunolocalization of Gelatinase $A$. Eightmicrometer cross-sections were cut in a cryostat at $-20^{\circ} \mathrm{C}$. The slides were washed with PBS at $4^{\circ} \mathrm{C}$, fixed for 5 minutes in $4 \%$ paraformaldehyde, and permeabilized with $0.1 \%$ Triton X-100 in PBS for 5 minutes. The slides were incubated overnight at $4^{\circ} \mathrm{C}$, with the first antibody diluted 1:20 in PBS containing $5 \%$ nonimmune sheep serum and $0.02 \% \mathrm{NaN}_{3}$. After PBS washes, the second antibody (sheep anti-rabbit immunoglobulin fluorescein isothiocyanate conjugate) diluted in PBS was added and incubated for 2 hours; then, spontaneous autofluorescence was abolished by Evans blue 1/10,000. The primary antibody was replaced by PBS or nonrelevant rabbit immunoglobulins directed to human thyroglobulin for negative control slides.

Immunolocalization of Rat TIMP-1. Eight-micrometer cross-sections were processed as described for gelatinase A. Similarly, the first antibody was diluted 1:20 in PBS.

\section{Lung Homogenate Rat IL-6 and TNF- $\alpha$ Concentration}

Lung homogenate was prepared as described for myeloperoxidase assay. Lung IL-6 and TNF- $\alpha$ concentrations were evaluated using specific rat ELISA according to the manufacturer's instructions (R\&D Systems, Inc., Minneapolis, MN). The sensitivity of this assay is $10 \mathrm{pg} / \mathrm{ml}$ for IL-6 and $5 \mathrm{pg} / \mathrm{ml}$ for TNF- $\alpha$.

\section{Statistical Analysis}

All data were expressed as means \pm SEM. One-way ANOVA and Fisher's least-significant difference test were used to detect statistically significant differences among the study groups in part one. The unpaired $t$ test was used in part two. The differences were considered significant when $p$ was less than 0.05 .

\section{References}

Clark JG, Milberg JA, Steinberg KP, and Hudson LD (1995). Type III procollagen peptide in the adult respiratory distress syndrome: Association of increased peptide levels in bronchoalveolar lavage fluid with increased risk for death. Ann Intern Med 122:17-23.

Curtis TM, Rotundo RF, Vincent PA, McKeown-Longo PJ, and Saba TM (1998). TNF- $\alpha$-induced matrix Fn disruption and decreased endothelial integrity are independent of Fn proteolysis. Am J Physiol (Lung Cell Mol Physiol 19) 275: L126-L138.

Davidson BA, Knight PR, Helinski JD, Nader ND, Shanley TP, and Johnson KJ (1999). The role of tumor necrosis factoralpha in the pathogenesis of aspiration pneumonitis in rats. Anesthesiology 91:486-499.

Delclaux C, Delacourt C, d'Ortho MP, Boyer V, Lafuma C, and Harf A (1996). Role of gelatinase $B$ and elastase in human polymorphonuclear neutrophil migration across basement membrane. Am J Respir Cell Mol Biol 14:288-295.

Delclaux C, d'Ortho MP, Delacourt C, Lebargy F, BrunBuisson C, Brochard L, Lemaire F, Lafuma C, and Harf A 
(1997a). Gelatinases in epithelial lining fluid of patients with adult respiratory distress syndrome. Am J Physiol (Lung Cell Mol Physiol 16) 272:L442-L451.

Delclaux C, Rezaiguia-Delclaux S, Delacourt C, BrunBuisson C, Lafuma C, and Harf A (1997b). Alveolar neutrophils in endotoxin-induced and bacteria-induced acute lung injury in rats. Am J Physiol (Lung Cell Mol Physiol 17) 273:L104-L112.

D'Haese A, Wuyts A, Dillen C, Dubois B, Billiau A, Heremans $\mathrm{H}$, Van Damme J, Arnold B, and Opdenakker G (2000). In vivo neutrophil recruitment by granulocyte chemotactic protein-2 is assisted by gelatinase B/MMP-9 in the mouse. $\mathrm{J}$ Interferon Cytokine Res 20:667-674.

d'Ortho MP, Clerici C, Yao PM, Delacourt C, Delclaux C, Franco-Montoya ML, Harf A, and Lafuma C (1997). Alveolar epithelial cells in vitro produce gelatinases and tissue inhibitor of matrix metalloproteinase-2. Am J Physiol (Lung Cell Mol Physiol 17) 273:L663-L675.

Folkesson HG, Matthay MA, Hébert CA, and Broaddus VC (1995). Acid aspiration-induced lung injury in rabbits is mediated by interleukin-8-dependent mechanisms. J Clin Invest 96:107-116.

Fowler AA, Hyers TM, Fisher BJ, Bechard DE, Centor RM, and Webster RO (1987). The adult respiratory distress syndrome: Cell populations and soluble mediators in the air spaces of patients at high risk. Am Rev Respir Dis 136:12251231.

Galis ZS, Sukhova GK, Lark MW, and Libby P (1994). Increased expression of matrix metalloproteinases and matrix degrading activity in vulnerable regions of human atherosclerotic plaques. J Clin Invest 94:2493-2503.

Gipson TS, Bless NM, Shanley TP, Crouch LD, Bleavins MR, Younkin EM, Sarma V, Gibbs DF, Tefera W, McConnell PC, Mueller WT, Johnson KJ, and Ward PA (1999). Regulatory effects of endogenous protease inhibitors in acute lung inflammatory injury. J Immunol 162:3653-3662.

Goldman G, Welbourn R, Kobzik L, Valeri CR, Shepro D, and Hechtman HB (1992). Reactive oxygen species and elastase mediate lung permeability after acid aspiration. J Appl Physiol 73:571-575.

Hayashi T, Stetler-Stevenson WG, Flemming MV, Fishback N, Koss MN, Liotta LA, Ferrans VJ, and Travis WD (1996). Immunohistochemical study of metalloproteinases and their tissue inhibitors in the lungs of patients with diffuse alveolar damage and idiopathic pulmonary fibrosis. Am J Pathol 149:1241-1256.

Horvath CJ, Ferro TJ, Jesmok G, and Malik AB (1988). Recombinant tumor necrosis factor increases pulmonary vascular permeability independent of neutrophils. Proc Natl Acad Sci USA 85:9219-9223.

Idell S, Kucich U, Fein A, Kueppers F, James HL, Walsh PN, Weinbaum G, Colman RW, and Cohen AB (1985). Neutrophil elastase-releasing factors in bronchoalveolar lavage from patients with adult respiratory distress syndrome. Am Rev Respir Dis 132:1098-1105.

Knight PR, Druskovich G, Tait AR, and Johnson KJ (1992). The role of neutrophils, oxidants, and proteases in the pathogenesis of acid pulmonary injury. Anesthesiology 77: 772-778.

Kondoh Y, Taniguchi H, Taki F, Tagaki K, and Satake T (1992). 7S collagen in bronchoalveolar lavage fluid of patients with adult respiratory distress syndrome. Chest 101:10911094.

Lacherade JC, Van de Louw A, Planus E, Escudier E, d'Ortho MP, Lafuma C, Harf A, and Delclaux C (2001). Evaluation of basement membrane degradation during TNF- $\alpha$-induced increase in epithelial permeability. Am J Physiol (Lung Cell Mol Physiol) 281:L134-L143.

Lee CT, Fein AM, Lipmann M, Holtzman H, Kimbel P, and Weinbaum G (1981). Elastase activity in pulmonary lavage fluid from patients with adult respiratory distress syndrome. N Engl J Med 304:192-196.

Li XY, Donaldson K, Brown D, and MacNee W (1995). The role of tumor necrosis factor in increased airspace epithelial permeability in acute lung inflammation. Am J Respir Cell Mol Biol 13:185-195.

Lotz M and Guerne PA (1991). Interleukin-6 induces the synthesis of tissue inhibitor of metalloproteinases-1/erythroid potentiating activity (TIMP-1/EPA). J Biol Chem 266:20172020.

Martin TR, Pistorese BP, Chi EY, Goodman RB, and Matthay MA (1989). Effects of leukotriene B4 in the human lung: Recruitment of neutrophils into the alveolar spaces without a change in protein permeability. J Clin Invest 84:1609-1619.

McGuire WW, Spragg RG, Cohen AB, and Cochrane CG (1982). Studies on the pathogenesis of the adult respiratory distress syndrome. J Clin Invest 69:543-553.

Motosugi H, Quinlan WM, Bree M, and Doerschuk CM (1998). Role of CD11b in focal acid-induced pneumonia and contralateral lung injury in rats. Am $\mathrm{J}$ Respir Crit Care Med 157:192-198.

Nagase T, Ishii S, Kume K, Uozumi N, Izumi T, Ouchi Y, and Shimizu T (1999). Platelet-activating factor mediates acidinduced lung injury in genetically engineered mice. J Clin Invest 104:1071-1076.

Pardo A, Selman M, Ridge K, Barrios R, and Sznajder J (1996). Increased expression of gelatinases and collagenase in rat lungs exposed to $100 \%$ oxygen. Am J Respir Crit Care Med 154:1067-1075.

Parsons PE, Sugahara K, Cott GR, Mason RJ, and Henson PM (1987). The effect of neutrophil migration and prolonged neutrophil contact on epithelial permeability. Am J Pathol 129:302-312.

Partridge CA, Jeffrey JJ, and Malik AB (1993). A 96-kDa gelatinase induced by TNF- $\alpha$ contributes to increased microvascular endothelial permeability. Am J Physiol (Lung Cell Mol Physiol 9) 265:L438-L447.

Piedboeuf B, Johnston CJ, Watkins RH, Hudak BB, Lazo JS, Cherian MG, and Horowitz S (1994). Increased expression of tissue inhibitor of metalloproteinases (TIMP-I) and metallothionein in murine lungs after hyperoxic exposure. Am J Respir Cell Mol Biol 10:123-132.

Roberts BL, Markland W, Ley AC, Kent RB, White DW, Guterman SK, and Ladner RC (1992). Directed evolution of a protein: selection of potent neutrophil elastase inhibitors displayed on M13 fusion phage. Proc Natl Acad Sci USA 89:2429-2433.

Sallenave JM, Donnelly SC, Grant IS, Robertson C, Gauldie J, and Haslett C (1999). Secretory leukocyte proteinase inhibitor is preferentially increased in patients with acute respiratory distress syndrome. Eur Respir J 13:1029-1036. 
Sallenave JM, Shulmann J, Crossley J, Jordana M, and Gauldie J (1994). Regulation of secretory leukocyte proteinase inhibitor (SLPI) and elastase-specific inhibitor (ESI/Elafin) in human airway epithelial cells by cytokines and neutrophilic enzymes. Am J Respir Cell Mol Biol 11:733-741.

Simon RH, DeHart PD, and Todd RF III (1986). Neutrophilinduced injury of rat pulmonary alveolar epithelial cells. J Clin Invest 78:1375-1386.

Taylor AE and Gaar KA (1970). Estimation of equivalent pore radii of pulmonary capillary and alveolar membrane. Am J Physiol 218:1133.

Torii K, lida KI, Miyazaki Y, Saga S, Kondoh Y, Taniguchi H, Taki F, Takagi K, Matsuyama M, and Suzuki R (1997). Higher concentrations of matrix metalloproteinases in bronchoalveolar lavage fluid of patients with adult respiratory distress syndrome. Am J Respir Crit Care Med 155:43-46.

Vieillard-Baron A, Frisdal E, Eddahibi S, Deprez I, Baker AH, Newby AC, Berger P, Leavame M, Raffestin B, Adnot S, and d'Ortho MP (2000). Inhibition of matrix metalloproteinases by lung TIMP-1 gene transfer or doxycycline aggravates pulmonary hypertension in rats. Circ Res 87:418-425.
Wangensteen OD, Wittmers LE, and Johnson JA (1969). Permeability of the mammalian blood-gas barrier and its components. Am J Physiol 216:719-727.

Weiland JE, Davis WB, Holter JF, Mohammed JR, Dorinsky PM, and Gadek JE (1986). Lung neutrophils in the adult respiratory distress syndrome: Clinical and pathophysiologic significance. Am Rev Respir Dis 133:218-225.

Wewers MD, Herzyk DJ, and Gadek JE (1988). Alveolar fluid neutrophil elastase activity in the adult respiratory distress syndrome is complexed to alpha-2-macroglobulin. J Clin Invest 82:1260-1267.

Yano T, Deterding RR, Simonet WS, Shannon JM, and Mason RJ (1996). Keratinocyte growth factor reduces lung damage due to acid instillation in rats. Am J Respir Cell Mol Biol 15:433-442.

Yao PM, Buhler JM, d'Ortho MP, Lebargy F, Delclaux C, Harf $A$, and Lafuma $C$ (1996). Expression of matrix metalloproteinase gelatinases $A$ and $B$ by cultured epithelial cells from human bronchial explants. J Biol Chem 271:15580-15589. 